\title{
Sensory evaluation of a yogurt drink containing an omega-3 nanoemulsion with enhanced bioavailability
}

\author{
K. E. Lane, E. J. Derbyshire, C. J. Smith, K. Mahadevan and W. Li \\ Department of Food and Tourism Management, Manchester Metropolitan University (MMU), Hollings Campus, \\ Old Hall Lane, Manchester, M14 6HR
}

Long chain omega-3 polyunsaturated fatty acids (LC3PUFA) have been linked to a spectrum of health benefits, including healthy ageing ${ }^{(1)}$. Dietary surveys indicate that LC3PUFA are currently under consumed, particularly amongst non-fish eaters and vegetarians ${ }^{(2)}$. New food vehicles i.e. micro algae oils have been developed to bridge this gap ${ }^{(3)}$.

Nanoemulsions are systems with droplet sizes in range of 20 to $500 \mathrm{~nm}^{(4)}$. The incorporation of algae oil into foods using nanoemulsion has the potential to improve LC3PUFA bioavailability ${ }^{(5)}$. However, nanoemulsion may also affect the acceptability of foods, as oil flavour is enhanced due to increased droplet surface area ${ }^{(6)}$.

The aim of the present single-blinded sensory evaluation study was to determine whether study participants $(n=96)$ could detect differences when an algae oil nanoemulsion versus a bulk oil was integrated with a strawberry yogurt and tasted. All samples were prepared using a breakfast drinking yogurt, agave nectar and natural strawberry flavouring. A non-enriched control product with the same formulation was used for the consumer test. For the fortified products a dose of $750 \mathrm{mg}$ DHA/100 g yogurt was added as either bulk oil or nanoemulsion.

The triangular test was used as a compulsory choice procedure to determine differences between the bulk oil and nanoemulsion fortified products. To determine how the products may differ, seven attributes were chosen to assess consumer acceptability: 1) smell, 2) appearance, 3) flavour, 4) texture, 5) consistency, 6) aftertaste and 7) overall acceptability. Attributes were rated using a 9-point hedonic scale.

\begin{tabular}{|c|c|c|c|c|c|c|}
\hline \multirow{2}{*}{$\begin{array}{l}\text { Sample } \\
\text { Attribute }\end{array}$} & \multicolumn{2}{|c|}{ Bulk } & \multicolumn{2}{|c|}{ Nano } & \multicolumn{2}{|c|}{ Control } \\
\hline & Mean & SD & Mean & SD & Mean & SD \\
\hline Smell*** & $5.79^{\mathrm{AB}}$ & 1.72 & $5.35^{\mathrm{B}}$ & 1.72 & $6.17^{\mathrm{A}}$ & $\overline{1.52}$ \\
\hline Appearance & 5.49 & 1.40 & 5.43 & 1.30 & 5.31 & 1.54 \\
\hline Flavour*** & $6.23^{\mathrm{A}}$ & 1.98 & $3.65^{\mathrm{B}}$ & 2.00 & $6.31^{\mathrm{A}}$ & 1.74 \\
\hline Texture** & $5.59^{\mathrm{A}}$ & 1.61 & $4.23^{\mathrm{B}}$ & 1.54 & $5.6^{\mathrm{A}}$ & 1.82 \\
\hline Consistency & 4.17 & 1.67 & 4.23 & 1.54 & 3.96 & 1.65 \\
\hline Aftertaste $* * *$ & $5.57^{\mathrm{A}}$ & 1.73 & $3.46^{\mathrm{B}}$ & 1.87 & $5.75^{\mathrm{A}}$ & 1.70 \\
\hline Overall acceptability**** & $5.71^{\mathrm{A}}$ & 1.74 & $3.89^{\mathrm{B}}$ & 1.95 & $5.95^{\mathrm{A}}$ & 1.73 \\
\hline
\end{tabular}

(Data are presented as means and standard deviations. Different letters in rows denote means that are significantly different to one another ( $* * P \leq 0.01, * * * P \leq 0.001)$. Results were analysed using ANOVA with Tukey and Duncan's tests and a Bonferoni correction at 5 per cent.)

For the triangular test 59 per cent of the panel identified the nanoemulsion yogurt was different to the bulk oil product $(P<0.001)$. No statistically significant differences were found within the 3 samples when the appearance and consistency was compared. The consistency of the nanoemulsion product was rated closest to 'just right' (midscale). However, nanoemulsion of algae oil significantly affected the aroma, flavour, texture, aftertaste and acceptability of a strawberry yogurt drink in contrast to the bulk oil. Further trials are recommended using flavoured algae oil, which could improve the aroma, flavour and aftertaste thus increasing overall acceptability.

Thanks go to John Dobson at DSM UK and Martek Biosciences Corporation, Columbia for the donation of the 35 per cent DHA S algae oil.

1. Swanson D, Block R, Mousa SA. Omega-3 Fatty Acids EPA and DHA: Health Benefits Throughout Life. Adv Nutr. 2012 January 1, $2012 ; 3(1): 1-7$.

2. Bates B, Lennox A, Swan G. National Diet and Nutrition Survey, Headline results from year 1 of the rolling programme. London: Food Standards Agency and Department of Health 2010.

3. Breivik H, editor. Long-Chain Omega-3 Speciality Oils. Bridgwater: The Oily Press; 2007.

4. Solans C, Solé I. Nano-emulsions: Formation by low-energy methods. Curr Opin Colloid Interface. 2012;17(5):246-54.

5. Acosta E. Bioavailability of nanoparticles in nutrient and nutraceutical delivery. Curr Opin Colloid Interface 2009;14(1):3-15.

6. Monsalve-Gonzalez A, Ochomogo M, inventors; Natural Flavor Enhancement Compositions for Food Emulsions. United States 2009. 